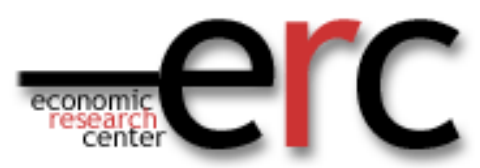

ERC Working Papers in Economics 15/03

April/ 2015

\title{
Inequality of Opportunities of Educational Achievement in Turkey over Time
}

\author{
Aysit Tansel \\ Department of Economics, Middle East Technical University, Ankara, Turkey and \\ Institute for the Study of Labor (IZA) Bonn, Germany and \\ Economic Research Forum (ERF) Cairo, Egypt \\ E-mail: atansel@metu.edu.tr \\ Phone: + (90) 3122102073
}




\title{
INEQUALITY OF OPPORTUNITIES OF EDUCATIONAL ACHIEVEMENT IN TURKEY OVER TIME*
}

\author{
Aysit Tansel \\ Department of Economics, Middle East Technical University, 06531 Ankara, Turkey; \\ Institute for Study of Labor (IZA), P.O. Box 7240, D-53072 Bonn, Germany; and \\ Economic Research Forum (ERF) Cairo, Egypt. \\ E-mail: atansel@metu.edu.tr, \\ Telephone: +903122102073 \\ Fax: 903122107964
}

April 22, 2015

\begin{abstract}
:
This study investigates inequality of opportunity in educational achievements in Turkey over time. For this purpose we use test scores of PISA in mathematics, science and reading achievement of 15-year-olds over the period 2003-2012. Since the different waves of the samples cover only a fraction of the cohorts of 15-year olds we take into account the inequality of opportunity in access to the PISA test as well as the inequality of opportunity of the academic achievement in the PISA test. This procedure enables proper over time comparisons. We estimate the effect of circumstances children are born into on their academic achievement as evidenced in their PISA test scores. The main findings are as follows. First, confirming the previous studies we find that inequality of opportunity is a large part of the inequality of educational achievement in Turkey. Second, the inequality of opportunity in educational achievement shows a slightly decreasing trend over time in Turkey. Third, the inequality of opportunity figures based on the mathematics, science and reading achievements exhibited the similar trend over time. Forth, the family background variables are the most important determinants of the inequality in educational achievement which is a consistent pattern over time. However, there is also evidence of slight weakening of these factors over time. Policies are necessary to improve equality of opportunity in education in Turkey.

JEL Classification: I24, D63

Keywords: Inequality of opportunity, Education, Turkey

*Earlier versions of this paper is presented at the Economic Research Forum (ERF) Annual Conference in Cairo, Egypt on March 22-24, 2014 and at the ERF Training Workshop on Measurements of Inequality of Opportunity and Inequality of Outcomes on January 13-15, 2013, Cairo, Egypt. I benefitted from the comments of the participant of these meetings as well as from a discussion with Luis Fernando Gamboa. I also would like to thank Ali Panal from the Ministry of National Education of Turkey for his kind help in securing the data used in this study and Yasemin Aslan and Mahmut Demirok for their programming assistance. Any errors are my own.
\end{abstract}




\section{Introduction}

In the literature on social justice two different concepts of inequality are advanced. They are inequality of outcomes and inequality of opportunities. Influential writers on this topic such as Dworkin (1981a and 1981b) Sen (1985), Arneson (1989) and Cohen (1989) have argued that fairness of a given allocation should not be judged by the inequality in the distribution of outcomes.

Roemer (1998) popularized the concept of "inequality of opportunity" He referred to outcomes as advantages and distinguished between the inequalities in advantages that are due to the "circumstances" and inequalities in advantages that are due to the "effort". Circumstances are the reasonably held responsible such as, gender, race or family background. Efforts are the factors for which individual can be held responsible such as, choices made and the effort expended in work. Accordingly, Roemer defines "inequality of opportunity" as a state of affairs in which the distribution of advantages is independent of the circumstances. He further contends that inequalities that are due to circumstances are unjust and should not be tolerated. However, the inequalities that are due to the efforts of the individuals and the choices made by them are acceptable.

In the literature on inequality of opportunities several advantages are considered. The advantage that is studied most often is income or consumption. Such studies include for instance Ferreira and Gignoux (2011). The second most studied advantage is educational achievement such as those by Ferreira and Gignoux (2010) and Salehi-isfahani et al. (2014). Finally, there are a few studies on the advantage of child health such as that by Assaad et al. (2012).

This paper considers the advantage of educational achievement in Turkey. Inequality of opportunity in educational achievement is examined using the results of the Programme for International Student Assessment (PISA) conducted by the Organization for Economic Cooperation and Development (OECD). We use four waves of PISA test scores in mathematics, science and reading for period 2003-2012. In examining the inequality of opportunity in education this study takes into account both the inequality of opportunity 
of the academic achievement in the PISA tests. Our results confirm the previous findings that inequality of opportunity is significantly large part of the inequality in educational achievement. Over time examination shows a slight increase in the inequality of opportunity in educational achievement over the past 10 years. The inequality of opportunity figures based on test scores in mathematics, science and reading are similar. The family background variables are the most important determinants of the inequality of educational achievement which seems to have weakened slightly over time.

The remainder of this paper is organized as follows. Section 2 briefly reviews the studies on the inequality of educational achievement in Turkey. Section 3 briefly summarizes the methodology used in examining the index of inequality of opportunity. Information on the four PISA surveys used in the empirical application is discussed in Section 4. The main empirical results are presented in Section 5. Section 6 gives the concluding remarks.

\section{Review of Literature}

There are several studies that examine the inequality of educational achievement in Turkey. One of the earliest ones is by Ferriera and Gignoux (2010). It is also the article that concentrates exclusively on Turkey in investigating the nature and magnitude of unequal opportunities in education. They find that there are significant differentials in enrollment due to gender and region of residence. They find that disadvantageous circumstances affect girls more adversely than boys. Next, they use PISA test scores for 2006 and find that the share of inequality of opportunity in educational achievement in total educational inequality in about 26-27 percent when no correction for sample selection bias is made. When they correct for selection inequality of opportunity rises to 27-33 percent. Family background factors such as ownership of durable goods, book and cultural possession account for 75-80 percent of the index of inequality of opportunity. One of their main findings is that although girls are disadvantaged in access to education, conditional on being in school gender is not an important determinant of achievement. 
There are two other studies that provide information on the inequality of educational opportunity in Turkey while at the same time reporting on other countries. One is by Salehi-isfahani et al. (2012) which consider inequality of educational achievement in the Middle East and North African countries. (MENA). They use non-parametric and parametric methods using test scores in mathematics and science from the Trends in Mathematics and Science Study (TIMSS) conducted by the International consortium. Their parametric results using several General Entropy (GE) indices indicate that Turkey is the highest inequality of opportunity in educational achievement county among the MENA countries with about 39 percent in mathematics scores and 37 percent in the science scores one of the top three MENA countries. Further, this inequality of opportunity in Turkey has increased over time from 17.6 percent in mathematics and 16.6 percent in science in 1999 (as one of the most opportunity equal country in MENA) to 38.8 percent in mathematics to 36.5 percent in science in 2007 (as one of the most opportunity unequal country in MENA. Further, the contribution of family background factors to inequality of opportunity in mathematics was about 0.807 and the contribution of community characteristics to the same was about 0.451 in 2007 . These results indicate the large role of family background in inequality of opportunity in education in Turkey.

In the recent paper Natkhov and Kozina (2012) also provide information on inequality of opportunity in educational achievement in Turkey along with information on a large number of countries. They use 2009 PISA data and a parametric method and the R-square from the regression of test scores on circumstances variables. They find that inequality of opportunity index in Turkey in 2009 is about 30 percent in mathematics, 24 percent in science and 31 percent in reading. With the index figure in mathematics Turkey ranks number 10 as the most unequal in a sample of 72 countries. In this sample Panama was found as the most unequal opportunity (with 35 percent) country based on its mathematics test scores while Azerbaijan was the least unequal opportunity (with 4.8 percent) country based on its mathematics test scores.

There are several studies on inequality of opportunity and private tutoring in Turkey. They discuss how private tutoring contributes to inequality of opportunity among the students. Private tutoring institutions prepare students for the nationwide highly 
competitive entrance examinations to the universities and selective good quality high schools. Access to private tutoring institutions is mainly determined by the family income. Thus indirectly family income determines who will attain university education and as a result succeed in the labor market and the society. Such issues are addressed by Tansel (2013a, 2013b), Tansel and Berberoglu (2015), Tansel (2014).

\section{Methodology}

The methodology used in the computation if the inequality of educational achievement is briefly described in this section. There are non-parametric and parametric methods of addressing this issue. In this paper we employ the parametric methods developed in the works by Bourguigno, Ferreira and Monendez (2007); Lefranc Pistolesi; and Trannoy (2009); Checchi and Paragine (2010) and Ferreira and Gignoux (2011a).

Ferreira and Gignoux (2011) develop an absolute and a relative version of the measure of inequality of opportunity with an application to the advantage of income/consumption. With the parametric methods it is possible to take into account a larger number of circumstances than it is the case with non-parametric methods albeit at the cost of making strong assumptions about the form of functional relationships between the advantages and the circumstances. A reduced form model of advantages as a function of circumstances and efforts can be estimated by the method of Ordinary Least Squares (OLS). In such a formulation the estimated parameters reflect both the direct effect and the indirect effect of circumstances through efforts on the advantage. In the notation of Ferreira and Gignoux (2011) the parametrically standardized estimates for the inequality of opportunity indices are given by

$$
\begin{aligned}
& \theta_{\mathrm{a}}^{\mathrm{ps}}=E_{0}(y)-E_{0}(\mathrm{v} \text { tilda }) \\
& \theta_{\mathrm{r}}^{\mathrm{ps}}=1-E_{0}(\mathrm{v} \text { tilda }) / E_{0}(y)
\end{aligned}
$$

Where y denotes the advantage; PS stands for parametrically standardized distributions. a stands for the index in levels and $r$ stands for the relative index. $\mathrm{E}_{0}$ is the mean logarithmic 
deviation which is a member of the generalized entropy class when its parameter is set to zero.

Here it must be emphasized that these indices are lower-bound estimates of the inequality of opportunity since in any application, the number of factors included as the circumstances are necessarily less than the true number of factors.

An important advantage of the parametric approach is that it allows the estimation of partial effects of one or more circumstance variables while controlling for the other circumstance factors.

We now mention one important complication with the use of PISA data sets. These data sets cover only a limited portion of the population of the 15 - year - old individuals. There are three main reasons for this in the PISA tests scores. As explained by Carvalho et al. (2012), first, not all off the 15 - year - olds individuals are enrolled in school. Second, some of the 15 - year - olds are enrolled in low grades due to grade repeating. Third, "logistic difficulties in the application of the test". Finally, some schools may be excluded based on physical or intellectual deficiencies of the students. Further these rates vary over time and across countries. In most of the developed countries the coverage rate of the 15-year-old population is above 80 percent in PISA. In Switzerland it is almost 100 percent in PISA in 2006. However, the coverage rates are around 50 percent in Turkey.

Paes de Barros et al. (2009) and Peragine (2011) articulate that lack of access to a given advantage is more important and serious than the achievement in the test by the individuals for whom such advantage is accessible. Therefore, inequality in opportunity for access to education is as important (may be more important) as inequality of opportunity in achievement. Since PISA does not collect information about nonparticipant individuals the Heckman's correction procedure can't be applied.

This issue of sample selection and not observing those who did not take the test is addressed recently by several researchers. Ferreira and Gignoux (2011) addresed this issue by reconstructing a full sample of 15 - year - old individuals. Ferreira and Gignoux 
(2011) reconstructed full samples for Brazil, Indonesia, Mexico and Turkey. These countries had low coverage rates. They used ancillary data bases such as household surveys for reconstruction of the full sample of 15-year olds. They performed two different kinds of simulations by imposing some assumptions. In one simulation they reweighted the test scores observations in PISA by the fraction of different types of individuals in the population taken from ancillary databases.

\begin{tabular}{|l|l|l|l|}
\hline & Without any & $\begin{array}{l}\text { Correction Assuming } \\
\text { Selection on } \\
\text { Observables }\end{array}$ & $\begin{array}{l}\text { Correction Assuming } \\
\text { Strong Selection on } \\
\text { Unobservables }\end{array}$ \\
\hline Reading & 0,251 & 0,250 & 0,327 \\
\hline Mathematics & 0,241 & 0,236 & 0,320 \\
\hline Science & 0,249 & 0,250 & 0,326 \\
\hline
\end{tabular}

In the second simulation they ascribed scores to the non-participating individuals in the ancillary surveys. They assigned the lowest score or the highest score obtained by individuals very similar to them. There are two problems with this approach. One is that the ancillary data sets used for reconstructing the full sample of 15 - year - old individuals may not be comparable over time or across countries. This procedure requires many different country-specific survey data sets which may have different definitions for types. Second problem is that in the process of assigning scores to the individuals who did not take the test, strong assumptions need to be made. The table above gives inequality of achievement and opportunity under different assumptions on selection into the PISA sample in Turkey as reported by Ferreira and J. Gignoux (2011).

Carvalho et al. (2012) follow a different route than Ferreira and Gignoux. They do not try to reconstruct a full sample. They recognize that there are two different dimensions of opportunity. One is access to the exam say to the PISA test or the TIMSS test. Second is the achievement conditional on access which is what we have studied. They then develop a bi-dimensional index of equality of opportunity. This index takes into account the access dimension and the achievement dimension. For the equality of opportunity in the 
achievement dimension we compute the conventional inequality of opportunity in test scores.

Carvalho et al. (2012) propose two methods. One is to use the coverage rate as the second dimension of our index. let $\dot{\mathrm{p}}$ denote the overall coverage rate. 0 indicates no coverage 1 indicates full coverage. The two dimensions are aggregated and Carvalho et al. (2012) call this "Bi-dimensional Index of Equality of Educational Opportunity" (BIE). They suggest two aggregation procedures. One is multiplication and the other is fuzzy sets technique. Then there are four versions of BIE. This index is increasing in $\dot{p}$ and decreasing in IO. The higher the coverage rate the higher the $\mathrm{BIE}_{1}$ implying that the larger is the opportunities offered to 15 - year - olds. In case $\dot{p}=1$, (full coverage) the $\mathrm{BIE}_{1}$ will depend only on inequality of opportunity in achievement. Other BIE measures use the overall coverage rate as the measure of access but aggregation is achieved through the fuzzy sets technique.

In the empirical application section parametric methods will be implemented using Carvalho et al. (2012) to take into account the selection into PISA sample.

\section{The Data}

PISA tests were administered for the first time in 2000 and every three years there after. It is administered by the OECD. 30 OECD countries as well as a number of non-OECD countries participate in the PISA tests. Tests are given in mathematics science and reading to a sample of 15-year old students.

Turkey did not participate in PISA in 2000. However, the PISA results for Turkey are available for 2003, 2006, 2009 and 2012 and are used in this study.

Two main differences between PISA and TIMSS tests are that, while PISA is given in the areas of mathematics, science and reading, TIMSS is given only in mathematics and science. PISA is administered to 15-year-old students which cover students in grades 7 
and up. TIMSS is given to students in the $4^{\text {th }}$ and $8^{\text {th }}$ grades. The $8^{\text {th }}$ grade covers students around 14 years of age. TIMSS is a curriculum based examination while PISA questions are based on life applications of curriculums in the relevant subject areas.

In 2012 the PISA tests were administered in 65 countries which represented 80 percent of the world economy. A total of 510 thousand students representing a total of 28 million students took the PISA tests. In Turkey the PISA tests are administered on April 22-30, 2012 in 170 schools in 57 provinces with participation of about 5 thousand students.

Turkey, since its first participation in the PISA tests in 2003, has been the third country from the bottom. This situation has not changed also in 2012. Turkey ranks as $44^{\text {th }}$ among the 65 countries in mathematics with a score of 448 and $43^{\text {rd }}$ in science with a score of 475 and $42^{\text {nd }}$ in reading with a score of 475 . Similarly, among the 34 OECD member countries Turkey ranks as $32^{\text {nd }}$ in mathematics, $32^{\text {nd }}$ in science and $31^{\text {st }}$ in reading. The mathematics score of Turkey 448 is blow the OECD average of 494. The science score of Turkey, 463 is below the OECD average of 501 and reading score of Turkey 475 is also below the OECD average of 496. An interesting aspect of the test is that girls surpass boys by about 10 points. While boys score higher in mathematics than girls, girls score higher than boys in science and reading.

According to the 2012 PISA test results in mathematics the first five positions are occupied by the far eastern countries as follows: Shanghai-China, Singapore, TaipeiChina and South-Korea. The similar list in science is as follows. Shanghai-China, Hong Kong-China, Japan and Finlandia. The similar list in reading is as follows. ShanghaiChina, Hong Kong-China, Japan and South Korea. As it is observed, Shanghai-China ranks as the top country in all of the three test scores.

Table 1 presents the number of observations and the main scores for mathematics, science and reading tests of PISA over the period 2003-2012. As it is observed in this table in the four waves of PISA tests considered in this study the mean scores for all of the mathematics, science and reading tests have increased over time. However, as remarked earlier this did not change the position of Turkey in the international rankings of countries 
as the third country from the bottom, although in each of the tests there was an increase in the proportions of the best performers and a decrease in the proportions of the worst performers over time. Further details about Turkey's scores in PISA tests can be found in Ministry of National Education (2013).

\section{Empirical Results}

As explained in the methodology section we use the parametric methods developed in the recent literature. We compute the share of circumstances in the inequality of PISA test scores in mathematics, science and reading. Circumstances affect educational attainment but are beyond the individual's control. The use of parametric methods is preferred in this application since they allow the control of a larger number of circumstances factors than the non-parametric methods albeit at the cost of a linear functional form assumption. An additional advantage of the parametric methods is that they allow measuring the partial effect of circumstances on advantages.

We follow Ferreira and Gignoux (2010) and chose variance as the inequality of indicator since the standardized PISA scores follow the normal distribution with an arbitrary mean. Then the parametric estimate of the share of inequality of opportunity is given by the coefficient of determination (R-square) of a linear regression of test scores on various circumstance factors. For the computation of the partial effect of a group of circumstances we follow Ferreira and Gignoux (2009).

Tables 2, 3 and 4 report respectively regressions of reading, mathematics and science scores on a number of circumstance factors in 2006. The regression estimates for the other years are available upon request from authors. These circumstance factors include gender, father's education (four categories), mother's education (four categories) and father's occupation (four categories). 
The categories of father's and mother's education are illiterate (base), no education, primary, secondary and tertiary. The categories of father's occupation are non-skilled employment in agriculture (base), legislators and service workers.

The variable language takes the value of one if the language of the test is the same as the language spoken at home. Migrant indicates if the child or one of his/her parents are born out of the country.

The variable book indicates the number of books available at home. Further, the set of variables dishwasher, dvd, phone, tv, computer and cars indicate their availability to the household. The next three variables indicate the availability of book on literature, poetry and arts. Finally, we have included a set of dummy variables indicating the seven regions of Turkey where south-east region is the base.

Table 5 provides the simple (uni-dimensional) and the bi-dimensional indices of inequality of opportunity computed as explained by the Carvalho et al. (2012) taking into account selection into the PISA sample.

We observe that the coverage rate of the 15-year old students is less than half except in the 2009 sample. The coverage rates are not uniform over the years which indicate the necessity of taking selection into PISA sample into account Therefore, the table 4 also reports the bi-dimensional equality of opportunity in achievement and access which in some cases reverse the order.

The figures in Table 5 indicate a substantial decline in inequality of opportunity from the high levels in 2003 and smaller declines in the recent years of 2009 and 2012. In the last two years of 2009 and 2012 the inequality of opportunities using mathematics scores are higher than those based on the science and the reading scores.

Table 6 gives the contributions of family background variables and community circumstances to inequality of opportunity. This table indicates that family background 
variables are more important than community characteristics and their importance have decline somewhat overtime from 2003 to 2012.

\section{Conclusions}

This study investigates inequality of opportunity in educational achievements in Turkey over time during the past 10 years. For this purpose we use test scores of PISA in mathematics, science and reading achievement of the 15-year-old students over the period 2003-2012. Since the different waves of the samples cover only a fraction of the cohorts of 15-year olds we take into account the inequality of opportunity in access to the PISA test as well as the inequality of opportunity of the academic achievement in the PISA test. This procedure enables us to make proper over time comparisons since the coverage rate of 15-year-olds differ over time in Turkey. We estimate the regressions of test scores on a number of circumstances children are born into. The salient findings of this study are as follows. First, confirming the previous studies we find that inequality of opportunity is a large part (around one third to a-quarter) of the inequality of educational achievement in Turkey. Second, the inequality of opportunity in educational achievement shows a slightly decreasing trend over time in Turkey from 2003 to 2012. Third, the inequality of opportunity figures based on the mathematics, science and reading achievements exhibited the similar trend over time with slightly higher figures for the mathematics scores. Forth, the family background variables are the most important determinants of the inequality in educational achievement which is a consistent pattern over time. However, there is also evidence of slight weakening of the family background factors over time. Policies are necessary to improve equality of opportunity in education in Turkey especially by reducing the importance of family background factors.

\section{References}

Almas, I., A.W. Cappelen, J.T. Lind, E. O. Sorensen and B. Tungodden (2011) "Measuring Unfair (in)equality", Journal of Public Economics 95: 488-499. 
Assaad, Ragui, Caroline Kraft, Nadja. B. Hassine, and Djavad Salehi-Isfahani (2012) "Inequality of Opportunity in Child Health in the Arab World and Turkey," Middle East Development Journal, 4(2):

Arneson, Richard (1989) “Equality of Opportunity for Welfare”, Philosophical Studies, 56: 7793.

Barros, Ricardo, Francisco Ferreira, Jose Molinas and Jaime Saavedra (2009) Measuring Inequality of Opportunity in Latin America and the Caribbean. Washington, DC: The World Bank.

Bourguignon, François (1979): "Decomposable Income Inequality Measures”, Econometrica 47 (4): $901-920$

Bourguignon, François, Francisco Ferreira and Marta Menendez (2007): "Inequality of Opportunity in Brazil", Review of Income and Wealth, 53 (4): 585-618.

Carvalho, Márcia de, Luis Fernando Gamboa, and, Fábio D. Waltenberg (2012): “Equality of Educational Opportunity Employing Pisa Data: Taking Both Achievement and Access into Account" Universidad del Rosario Facultad de Economia, Working Paper No:130

Checchi, Daniele, \& Vito Peragine (2010): “Inequality of Opportunity in Italy,” Journal of Economic Inequality 8 (4): 429-450.

Dworkin, Ronald (1981a) "What is Equality? Part 1: Equality of Welfare," Philosophy and Public Affairs, 10: 185-246.

Dworkin, Ronald (1981b): "What is Equality? Part 2: Equality of Resources," Philosophy and Public Affairs, 10: 283-345. 
Ferreira, Francisco H. G. and Jérémie Gignoux, (2011): “The Measurement of Inequality of Opportunity: Theory and an Application to Latin America," Review of Income and Wealth, $\mathbf{5 7}$ (4): $622-657$.

Ferreira, Francisco H. G, Jérémie Gignoux and Meltem Aran (2011): "Measuring Inequality of Opportunity with Imperfect Data: The Case of Turkey," Journal of Economic Inequality 9 (4): 651-680.

Ferreira, Francisco H. G. and Jérémie Gignoux, (2010): “Inequality of Opportunity for Education: Turkey," in Ravi Kanbur and Michael Spence (eds), Equity in a Globalizing World, Commission on Growth and Development, Washington, (pp.131-56).

Ferreira, F., Gignoux, J. (2009),'Inequality of Economic Opportunity in Turkey: An Assessment Using Asset Indicators.” Unpublished paper, World Bank Development Research Group, Washington, DC.

Ferreira, F., Gignoux, J. (2011), “The Measurement of Educational Inequality: Achievement and Opportunity". Working Papers No: 240, ECINEQ, Society for the Study of Economic Inequality.

Ferreira, Francisco H. G., Jérémie Gignoux, and Meltem Aran, (2011) "Measuring Inequality of Opportunity with Imperfect Data: The Case of Turkey," Journal of Economic Inequality, 9: 651680.

Fleurbaey Marc and Vito Peragine (2013) "Ex ante versus ex post equality of opportunity," Economica, 80 (317): 118-130.

Gamboa, L. F. and F.D. Waltenberg (2012). "Inequality of Opportunity in Educational Achievement in LatinAmerica: Evidence from PISA 2006-2009," Economics of Education Review, 31(5): 694-708.

Lefranc, A., N. Pistolesi, and A. Trannoy (2009) "Equality of Opportunity and Luck: Definitions and Testable Conditions, with an Application to Income in France," Journal of Public Economics 93 (11-12): 1189-1207. 
Marrero, Gustavo A. and Juan G. Rodríguez, (2013): "Inequality of Opportunity and Growth," Journal of Development Economics, 104: 107-122.

Ministry of National Education, Republic of Turkey (2013). PISA 2012 National Report, Ankara: Yenilik ve Eğitim Teknolojileri Genel Müdürlüğü. www.meb.gov.tr, http://pisa.meb.gov.tr

Natkhov, Timur and Kozina, Natalia (2009): "Inequality of Educational Opportunity in a CrossSection of Countries. Empirical Analysis of 2009 Pisa Data," National Research University Higher School of Economics, Moscow, Russia. Working paper Series: Education WP BRP 07/EDU/2012.

Pignataro, Giuseppe (2011) "Equality of Opportunity: Policy and Measurement Paradigms," Journal of Economic Surveys, 26 (5): 800-834.

Pistolesi, Nicolas (2009): "Inequality of Opportunity in the Land of Opportunities, 1968-2001," Journal of Economic Inequality 7: 411-433.

Rawls, John (1971) A Theory of Justice, Cambridge, MA: Harvard University Press.

Roemer, John (1998) Equality of Opportunity, Cambridge, MA: Harvard University Press.

Salehi-Isfahani, Djavad, Nadia Belhaj Hassine and Ragui Assaad (2014) "Equality of Opportunity in Education in the Middle East and North Africa," The Journal of Economic Inequality, 12: 489-515.

Sen, Amartya (1980). "Equality of What?" In Tanner Lectures on Human Values, ed. S. McMurrin. Cambridge, MA: Cambridge University Press.

Tansel, Aysit (2002) "Determinants of Schooling Attainment for Boys and Girls in Turkey: Individual, Household and Community Factors," Economics of Education Review, 21: 455-470. 
Tansel Aysit and Fatma Bircan (2005) "Effect of Private Tutoring on University Entrance Examination Performance in Turkey," Institute for the Study of Labor (IZA) Working Paper No. 1609. Bonn, Germany. http://www.iza.org/dp1609.pdf

Tansel Aysit and Fatma Bircan (2006) "Demand for Education in Turkey: A Tobit Analysis of Private Tutoring Expenditures in Turkey,"Economics of Education Review, 25:303-313.

Tansel, Aysit (2013a): "Private Tutoring and Equitable Opportunities in Turkey: Challenges and Policy Implications," Mediterranean Journal of Educational Studies, also published in Bray, M., A. E. Mazawi and R .G. Sultana (Eds.) (2013) Private Tutoring Across the Mediterranean, Sense Publishers, Rotterdam. (pp. 177-186).

Tansel, Aysit (2013b) "Supplementary Education in Turkey: Recent Developments and Future Prospects," in J. Aurini, S. Davies and J. Dierkes (Eds.) Out of the Shadows: The Global Intensification of Supplementary Education (International Perspectives on Education and Society, Volume 22) Emerald Group Publishing Limited. (pp.23 - 66).

Tansel, Aysit (2014) “Inequality of Opportunity for Higher Education in Turkey,” Mimeo.

Department of Economics, Middle East Technical University, Ankara, Turkey.

Tansel Aysit and Giray Berberoğlu (2015) "Does Private Tutoring Increase Academic Performance of Students? Evidence from Turkey," International Review of Education, Forthcoming.

World Bank (2006) World Development Report: Equity and Development. Washington, DC: World Bank.

World Bank (2010) Turkey: "Expanding Opportunities for the Next Generation”, A Report on Life Changes, Europe and Central Asia Region Human Development Department, Report No: 48627-TR, Washington, DC. 
Table 1: Means and Standard Deviations of the PISA Test Scores, 2003-2012, Turkey

\begin{tabular}{|c|c|c|c|c|c|c|}
\hline Year & Variable & Obs & Mean & Std. Dev. & Min & Max \\
\hline 2003 & PVREAD & 4855 & 444 & 85 & 129 & 743 \\
\hline 2003 & PVMATH & 4855 & 427 & 98 & 143 & 831 \\
\hline 2003 & PVSCIE & 4855 & 436 & 86 & 156 & 749 \\
\hline Year & Variable & Obs & Mean & Std. Dev. & Min & Max \\
\hline 2006 & PVREAD & 4942 & 453 & 83 & 109 & 1079 \\
\hline 2006 & PVMATH & 4942 & 428 & 89 & 162 & 761 \\
\hline 2006 & PVSCIE & 4942 & 428 & 80 & 135 & 680 \\
\hline Year & Variable & Obs & Mean & Std. Dev. & Min & Max \\
\hline 2009 & PVREAD & 4996 & 465 & 85 & 118 & 813 \\
\hline 2009 & PVMATH & 4996 & 445 & 91 & 159 & 899 \\
\hline 2009 & PVSCIE & 4996 & 455 & 86 & 138 & 730 \\
\hline Year & Variable & Obs & Mean & Std. Dev. & Min & Max \\
\hline 2012 & PVREAD & 4848 & 475 & 82 & 110 & 818 \\
\hline 2012 & PVMATH & 4848 & 448 & 93 & 155 & 889 \\
\hline 2012 & PVSCIE & 4848 & 463 & 81 & 140 & 715 \\
\hline
\end{tabular}

Source: Authors' computations using PISA test scores for the period 2003-2012.

Note: PV stands for plausible value. 
Table 2: Regression of PISA Reading Scores on Various Indicators of Circumstances

\begin{tabular}{|c|c|c|}
\hline PVREAD & Coefficient & Std. Error. (T- Statistics) \\
\hline female & 30.26 & $2.13(14.19)$ \\
\hline noeducation & 26.96 & $6.13(4.40)$ \\
\hline secondary & 18.90 & $5.96(3.17)$ \\
\hline primary & 18.67 & $5.71(3.27)$ \\
\hline tertiary & 10.26 & $4.94(2.08)$ \\
\hline noeducatio $\sim$ m & -19.55 & $8.79(-2.22)$ \\
\hline secondary_m & -14.49 & $7.39(-1.96)$ \\
\hline primary_m & -14.13 & $7.41(-1.91)$ \\
\hline tertiary_m & 21.16 & $3.57(5.91)$ \\
\hline legislator $\sim$ m & 5.19 & $6.21(0.84)$ \\
\hline services_m & -2.82 & $6.19(-0.46)$ \\
\hline skilleda_m & -2.42 & $6.20(-0.39)$ \\
\hline language & -1.96 & $6.71(-0.29)$ \\
\hline migrant & -16.06 & $6.44(-2.49)$ \\
\hline book & 11.49 & $1.14(10.03)$ \\
\hline dishwasher & -1.63 & $2.42(-0.68)$ \\
\hline dvd & .56 & $2.49(0.23)$ \\
\hline phone & 18.75 & $5.77(3.25)$ \\
\hline tv & -1.09 & $10.41(-0.11)$ \\
\hline computer & 17.66 & $2.45(7.20)$ \\
\hline cars & -.56 & $2.25(-0.25)$ \\
\hline literature & 35.91 & $2.48(14.47)$ \\
\hline poetry & -16.84 & $2.36(-7.12)$ \\
\hline
\end{tabular}




\begin{tabular}{|c|c|c|}
\hline art & 4.45 & $2.30(1.93)$ \\
\hline Marmara & 21.76 & $4.63(4.70)$ \\
\hline Mediterranean & 38.83 & $4.92(7.88)$ \\
\hline East Anatolia & -4.70 & $5.48(-0.86)$ \\
\hline Aegean & 47.32 & $5.09(9.29)$ \\
\hline Southeast Anatolia & (base) & \\
\hline Black Sea & 26.77 & $5.06(5.29)$ \\
\hline Central Anatolia & 30.72 & $4.84(6.34)$ \\
\hline Constant & 338.47 & $13.13(25.78)$ \\
\hline Number of Obs. & 4942 & \\
\hline$F(30,4911)$ & 59.61 & \\
\hline Prob $>$ F & 0.0000 & \\
\hline R-squared & 0.2669 & \\
\hline Adj. R-squared & 0.2625 & \\
\hline Root MSE & 76.719 & \\
\hline
\end{tabular}

Source: Authors' computations using PISA test scores for the period 2003-2012.

Note: PV stands for plausible value. 
Table 3: Regression of PISA Mathematics Scores on Various Indicators of Circumstances

\begin{tabular}{|c|c|c|}
\hline PVMATH & Coefficient & Std. Error (T- Statistics) \\
\hline female & -19.03 & $2.27(-8.35)$ \\
\hline No education & 23.86 & $6.55(3.64)$ \\
\hline secondary & 22.57 & $6.37(3.54)$ \\
\hline primary & 22.55 & $6.11(3.69)$ \\
\hline tertiary & 29.99 & $5.28(5.68)$ \\
\hline noeducatio $\sim$ m & -5.96 & $9.39(-0.63)$ \\
\hline secondary_m & -1.75 & $7.89(-0.22)$ \\
\hline primary_m & -5.37 & $7.92(-0.68)$ \\
\hline tertiary_m & 21.37 & $3.82(5.59)$ \\
\hline legislator $\sim$ m & 22.21 & $6.63(3.35)$ \\
\hline services_m & 13.08 & $6.61(1.98)$ \\
\hline skilleda_m & 17.59 & $6.63(2.65)$ \\
\hline language & -4.86 & $7.17(-0.68)$ \\
\hline migrant & 7.57 & $6.88(1.10)$ \\
\hline book & 15.37 & $1.22(12.55)$ \\
\hline dishwasher & 1.14 & $2.58(0.44)$ \\
\hline dvd & .69 & $2.66(0.26)$ \\
\hline phone & 26.60 & $6.17(4.31)$ \\
\hline tv & 10.10 & $11.12(0.91)$ \\
\hline computer & 22.48 & $2.62(8.57)$ \\
\hline cars & 3.19 & $2.40(1.33)$ \\
\hline literature & 31.71 & $2.65(11.96)$ \\
\hline
\end{tabular}




\begin{tabular}{|c|c|c|}
\hline poetry & -18.17 & $2.52(-7.19)$ \\
\hline art & -.72 & $2.46(-0.29)$ \\
\hline Marmara & 17.05 & $4.95(3.44)$ \\
\hline Mediterranean & 45.80 & $5.26(8.70)$ \\
\hline East Anatolia & -6.21 & $5.86(-1.06)$ \\
\hline Aegean & 47.36 & $5.44(8.70)$ \\
\hline Black Sea & 31.65 & $5.41(5.85)$ \\
\hline Central Anatolia & 37.49 & $5.17(7.24)$ \\
\hline Constant & 275.22 & $14.03(19.61)$ \\
\hline Number of Obs. & 4942 & \\
\hline$F(30,4911)$ & 59.61 & \\
\hline Prob $>$ F & 0.0000 & \\
\hline R-squared & 0.2669 & \\
\hline Adj. R-squared & 0.2625 & \\
\hline Root MSE & 76.719 & \\
\hline
\end{tabular}

Source: Authors' computations using PISA test scores for the period 2003-2012.

Note: PV stands for plausible value. 
Table 4: Regression of PISA Science Scores on Various Indicators of Circumstances

\begin{tabular}{|c|c|c|}
\hline PVSCIE & Coefficient & Std. Error (T- Statistics) \\
\hline female & .59 & $2.03(0.29)$ \\
\hline noeducation & 9.89 & $5.85(1.69)$ \\
\hline secondary & 6.30 & $5.69(1.11)$ \\
\hline primary & 7.11 & $5.45(1.30)$ \\
\hline tertiary & 24.05 & $4.71(5.10)$ \\
\hline noeducatio $\sim$ m & -11.67 & $8.39(-1.39)$ \\
\hline secondary_m & -5.23 & $7.05(-0.74)$ \\
\hline primary_m & -9.70 & $7.07(-1.37)$ \\
\hline tertiary_m & 22.33 & $3.41(6.54)$ \\
\hline legislator $\sim$ m & 14.15 & $5.93(2.39)$ \\
\hline services_m & 7.52 & $5.91(1.27)$ \\
\hline skilleda_m & 10.40 & $5.92(1.76)$ \\
\hline language & 1.71 & $6.40(0.27)$ \\
\hline migrant & -1.88 & $6.15(-0.31)$ \\
\hline book & 13.99 & $1.09(12.79)$ \\
\hline dishwasher & -1.00 & $2.31(-0.44)$ \\
\hline dvd & -.03 & $2.38(-0.02)$ \\
\hline phone & 18.16 & $5.51(3.29)$ \\
\hline tv & 3.74 & $9.94(0.38)$ \\
\hline computer & 19.01 & $2.34(8.12)$ \\
\hline cars & -.63 & $2.14(-0.29)$ \\
\hline literature & 33.91 & $2.36(14.31)$ \\
\hline
\end{tabular}




\begin{tabular}{|c|c|c|}
\hline poetry & -16.80 & $2.25(-7.44)$ \\
\hline art & 4.25 & $2.20(1.93)$ \\
\hline Marmara & 20.17 & $4.42(4.56)$ \\
\hline Mediterranean & 44.44 & $4.70(9.45)$ \\
\hline East Anatolia & 1.62 & $5.23(0.31)$ \\
\hline Aegean & 43.08 & $4.86(8.86)$ \\
\hline Black Sea & 39.42 & $4.83(8.16)$ \\
\hline Central Anatolia & 34.23 & $4.62(7.40)$ \\
\hline Constant & 308.48 & $12.53(24.61)$ \\
\hline Number of Obs. & 4942 & \\
\hline$F(30,4911)$ & 58.19 & \\
\hline Prob $>$ F & 0.0000 & \\
\hline R-squared & $=0.2623$ & \\
\hline Adj. R-squared & 0.2578 & \\
\hline Root MSE & 68.535 & \\
\hline
\end{tabular}

Source: Authors' computations using PISA test scores for the period 2003-2012.

Note: PV stands for plausible value. 
Table 5: Indices of Inequality of Educational Opportunity 2003, 2006, 2009, Turkey

\begin{tabular}{|c|c|c|c|c|}
\hline PISA 2003 & $\begin{array}{c}\text { Coverage } \\
\text { Rate }\end{array}$ & $\begin{array}{c}\text { Inequality } \\
\text { of Opportunity in } \\
\text { Achievement } \\
\text { (IO) }\end{array}$ & $\begin{array}{c}\text { Unidimensional } \\
\text { Equality of Opportunity } \\
\text { in Achievement }\end{array}$ & $\begin{array}{c}\text { Bidimensional Equality } \\
\text { of Opportunity in } \\
\text { Achievement and Access }\end{array}$ \\
\hline Reading & 35,6 & 0,3339 & 0,6561 & 0,2336 \\
\hline Mathematics & 35,6 & 0,3019 & 0,6381 & 0,2272 \\
\hline Science & 35,6 & 0,3112 & 0,6388 & 0,2274 \\
\hline PISA 2006 & & & & \\
\hline Reading & 47,3 & 0,2603 & 0,7397 & 0,3499 \\
\hline Mathematics & 47,3 & 0,2669 & 0,7331 & 0,3468 \\
\hline Science & 47,3 & 0,2623 & 0,7377 & 0,3489 \\
\hline PISA 2009 & & & & \\
\hline Reading & 57,4 & 0,2081 & 0,7919 & 0,4546 \\
\hline Mathematics & 57,4 & 0,2316 & 0,7584 & 0,4353 \\
\hline Science & 57,4 & 0,2110 & 0,789 & 0,4524 \\
\hline PISA $2012 *$ & & & & \\
\hline Reading & 50,7 & 0,2001 & 0,7999 & 0,4807 \\
\hline Mathematics & 50,7 & 0,2116 & 0,7884 & 0,4738 \\
\hline Science & 50,7 & 0,2083 & 0,7917 & 0,4758 \\
\hline
\end{tabular}

Source: Authors' computations using PISA test scores for the period 2003-2012.

Notes: *The figures for 2012 are based on incomplete and unofficial data. Complete results will be provided when the 2012 official data is released by the authorities. 
Table 6: The Contribution of Family Background and Community Characteristics to Inequality of Opportunity, 2003-2012, Turkey.

\begin{tabular}{|l|c|c|c|}
\hline Reading & All Circumstances & $\begin{array}{c}\text { Share of Family } \\
\text { Background }\end{array}$ & $\begin{array}{c}\text { Share of Community } \\
\text { Characteristics }\end{array}$ \\
\hline 2003 & 0.33 & 0.85 & 0.48 \\
\hline 2006 & 0.26 & 0.84 & 0.46 \\
\hline 2009 & 0.21 & 0.81 & 0.44 \\
\hline 2012 & 0.20 & 0.80 & 0.45 \\
\hline
\end{tabular}

\begin{tabular}{|l|c|c|c|}
\hline Math & 0.30 & 0.87 & 0.50 \\
\hline 2006 & 0.27 & 0.88 & 0.49 \\
\hline 2009 & 0.23 & 0.87 & 0.49 \\
\hline 2012 & 0.21 & 0.87 & 0.44 \\
\hline
\end{tabular}

\begin{tabular}{|l|c|c|c|}
\hline Science & 0.31 & 0.83 & 0.53 \\
\hline 2006 & 0.26 & 0.80 & 0.53 \\
\hline 2009 & 0.21 & 0.78 & 0.51 \\
\hline 2012 & 0.21 & 0.79 & 0.51 \\
\hline
\end{tabular}

Source: Authors' computations using PISA test scores for the period 2003-2012.

Note: PV stands for plausible value.

*The figures for 2012 are based on incomplete and unofficial data. Complete results will be provided when the 2012 official data is released by the authorities. 